\title{
Management of pregnancy associated venous-thromboembolism: a survey of practices
}

\author{
Esteban Gándara ${ }^{1,2,3^{*}}$, Marc Carrier ${ }^{1,2}$ and Marc A Rodger ${ }^{1,2}$
}

\begin{abstract}
Introduction: Low-molecular-weight heparin $(\mathrm{LMWH})$ is frequently recommended for the treatment of pregnancy associated venous thromboembolism (PAVTE). Given that prior reports have suggested a wide variation in dosing of LMWH in pregnancy and the use of anti-Xa monitoring in pregnancy, the principal aim of this survey was to assess current practices for the management of PAVTE.

Methods: An electronic survey was conducted. The target sample was members of the North American Society of Obstetric Medicine and Thrombosis Interest Group of Canada.

Results: The final sample consisted of 27/69 hematologists (39.1\%), 30/69 internists (43.5\%), 8/69 obstetricians $(11.6 \%)$, and $4 / 69$ from other specialties (5.7\%). For the acute treatment of patients pregnant patients with deep vein thrombosis 42/69 (60.8\%) preferred LMWH given twice a day 42/69 (60.8\%), whereas 25/69 (36.2\%) preferred once daily. These results were similar for patients with pulmonary embolism (PE). For long-term treatment more than $70 \%$ of the respondents favoured treatment with full doses of LMWH given once a day or twice a day and 16/69 (23.2\%) intermediate doses for patients diagnosed with DVT. These results were similar for patients with PE. Fourteen physicians out of 69 (20.3\%) did not measure anti-Xa monitoring during acute treatment period and 24/69 (34.8\%) never used anti-Xa levels during the long term treatment period. Management during the peri-partum period varied widely according to the time of the diagnosis of PAVTE.
\end{abstract}

Discussion: In conclusion, our survey shows wide variation in practice regarding LMWH dosing and anti-Xa monitoring in pregnancy associated VTE and calls for trials comparing different long term strategies using LMWH in patients with PAVTE.

Keywords: Pregnancy, Thrombosis, Heparin

\section{Introduction}

Low-molecular-weight heparin (LMWH) is frequently recommended for the treatment of pregnancy associated venous thromboembolism (PAVTE) [1]. Normal physiologic changes occurring during pregnancy affect the pharmacokinetics of LMWH that result in increasing dose requirements in pregnancy (due to a greater volume of distribution and increased renal clearance) [2]. Consequently in patients with PAVTE a more aggressive approach using continuous full doses of LMWH, given twice daily and tailored to anti-Xa levels is commonly

\footnotetext{
* Correspondence: egandara@ohri.ca

${ }^{1}$ From the Thrombosis Program, Division of Hematology, Department of Medicine, University of Ottawa-The Ottawa Hospital, Ottawa, Canada ${ }^{2}$ Clinical Epidemiology Unit, Ottawa Health Research Institute, Ottawa, Canada

Full list of author information is available at the end of the article
}

used [3,4] during the acute treatment period (first 1-4 weeks) and long-term treatment ( $>1-4$ weeks) without supporting evidence from high quality studies or current clinical guidelines [1]. The principal aim of this survey the principal aim of this survey was to assess current practices for the management of PAVTE.

\section{Methods}

An electronic self-response survey, using Survey Monkey software was conducted. The target sample was experts and clinicians with experience in the management of VTE associated with pregnancy. An information sheet/ electronic statement indicating that participation was voluntary and ensuring confidentiality was provided with each survey. Two groups agreed to collaborate with this project: 1-The Thrombosis Interest Group of Canada

\section{Biomed Central}


(TIGC) and 2-the International society of Obstetrics medicine (ISOM). The protocol was approved by the Ottawa Hospital Ethics and Research board to initiating the survey. The survey was pre-tested among nine thrombosis physicians at the Ottawa hospital, prior to being distributed. The evaluation of the current clinical practice was conducted using a multiple choice option format. Information regarding the type of heparin used for initial treatment and dosing; the type of heparin used for longterm-treatment and dosing; and finally the use of anti-Xa levels to guide therapy during the acute and long term treatment period was collected. Baseline characteristics of the respondents including years of practice, specialty, and knowledge about research methodology, was also captured. Finally, to ensure that the survey was answered by physicians with ample experience in the management of pregnancy associated VTE, a screening question was inserted at the beginning of the survey trying to identify physicians who have treated more than two PAVTE during the last year. This number was reached by consensus among two thrombosis experts (MR and MC).

The survey results are reported using descriptive statistics (percentages and 95\% CI). Stratified analysis was conducted by years of practice, specialty, and knowledge about research methods accordingly for each question. Data was collected using Microsoft excel, and the analysis was conducted using SAS.

\section{Results}

The survey was electronically mailed to 305 participants; 246 from the ISOM and 54 from TIGC. One hundred and five of 305 (35\%) started answering the survey, of which 5 (4.5\%) were disqualified after the initial screening question, and 69/305 (22.6\%) completed the entire survey. The final sample consisted of 27/69 hematologists (39.1\%), 30/69 internists (43.5\%), 8/69 obstetricians (11.6\%), and 4/69 from other specialties (5.7\%). Eight out of sixty nine had practiced medicine less than 5 years, $11 / 69$ (15.9\%) between 5 to 10 years, 14/69 (20.3\%) between 10 to 15 and 36/69 (52.1\%) more than 15 years.

For the acute treatment of pregnant patients with deep vein thrombosis (DVT), 42/69 (60.8\%) preferred LMWH given twice a day whereas $25 / 69$ (36.2\%) prescribed it once daily. These results were similar for patients with pulmonary embolism (PE), although $6 \%$ of the respondents favored UFH for the initial treatment period. More than $70 \%$ of the respondents favored treatment with full doses of LMWH given once a day or twice a day for long-term treatment ( $\geq 1$ month after initiation of anticoagulation). An intermediate dose (once a day) was used by a minority physicians for long term treatment [16/69 (23.2\%) for patients diagnosed with DVT and 15/69 (21.7\%) for patients diagnosed with PE]. Thirty two physicians out of 69 (46.3\%) reported using anti-Xa monitoring during the first 30 days in all patients and 16/69

Table 1 Summary of treatment strategies, peri-partum management and anti-Xa monitoring used by respondents

\begin{tabular}{|c|c|c|c|c|c|c|c|}
\hline & & $\begin{array}{l}\text { LMWH Full } \\
\text { dose BID }\end{array}$ & $\begin{array}{l}\text { LMWH Full } \\
\text { dose OD }\end{array}$ & UFH IV & UFH SC BID & $\begin{array}{l}\text { LMWH intermediate } \\
\text { dose OD }\end{array}$ & Other \\
\hline & & $\%(95 \% \mathrm{Cl})$ & $\%(95 \% \mathrm{Cl})$ & $\%(95 \% \mathrm{Cl})$ & $\%(95 \% \mathrm{Cl})$ & $\%(95 \% \mathrm{Cl})$ & $\%(95 \% \mathrm{Cl})$ \\
\hline \multirow[t]{2}{*}{ Acute treatment } & DVT & $62.3(50-73)$ & $36.2(25-48)$ & 0 & $1.4(0-7)$ & NA & $0.14(0-7)$ \\
\hline & PE & $62.3(50-73)$ & $29(19-40)$ & $5.8(2-13)$ & $1.4(0-7)$ & NA & $1.4(0-7)$ \\
\hline \multirow{4}{*}{$\begin{array}{l}\text { Long-term } \\
\text { treatment }\end{array}$} & DVT & $36.2(25-48)$ & $34.8(24-46)$ & NA & 0 & $23.2(14-34)$ & $5.8(2-13)$ \\
\hline & PE & $37.7(26-49)$ & $36.2(25-48)$ & NA & 0 & $21.7(13-32)$ & $4.4(1-11)$ \\
\hline & & Weekly & $\begin{array}{l}\text { Once a } \\
\text { month }\end{array}$ & $\begin{array}{c}\text { Weekly in special } \\
\text { populations* }\end{array}$ & $\begin{array}{l}\text { Once a month in } \\
\text { special populations* }\end{array}$ & Never & Other \\
\hline & & $\%(95 \% \mathrm{Cl})$ & $\%(95 \% \mathrm{Cl})$ & $\%(95 \% \mathrm{Cl})$ & $\%(95 \% \mathrm{Cl})$ & $\%(95 \% \mathrm{Cl})$ & $\%(95 \%$ Cl) \\
\hline \multirow{5}{*}{$\begin{array}{c}\text { Anti-Xa } \\
\text { monitoring }\end{array}$} & Acute treatment & $20.4(12-31)$ & $26(16-37)$ & $7.2(3-15)$ & $15.9(9-26)$ & $20.4(12-31)$ & 10.1 (4-19) \\
\hline & Long-term & $1.4(0-7)$ & $17.4(10-27)$ & $2.9(0-9.2)$ & $30.4(20-42)$ & $34.8(24-46)$ & $13.1(24-46)$ \\
\hline & Treatment & & & & & & \\
\hline & & $\begin{array}{l}\text { IVC filter + } \\
\text { LMWH BID }\end{array}$ & $\begin{array}{l}\text { IVC filter + } \\
\text { IV UFH }\end{array}$ & LMWH BID & UFH SC BID & UFH IV & Other \\
\hline & & $\%(95 \% \mathrm{Cl})$ & $\%(95 \% \mathrm{Cl})$ & $\%(95 \% \mathrm{Cl})$ & $\%(95 \% \mathrm{Cl})$ & $\%(95 \% \mathrm{Cl})$ & $\%$ \\
\hline \multirow{3}{*}{$\begin{array}{l}\text { Peri-partum } \\
\text { Management }\end{array}$} & VTE $>4$ weeks & 0 & 0 & $53.6(41-65)$ & $18.8(11-29)$ & $5.8(2-13)$ & $21.7(0-9.2)$ \\
\hline & $\begin{array}{c}\text { VTE }<4 \\
\text { and }>2 \text { weeks }\end{array}$ & 0 & $2.9(0-9.2)$ & $31.9(21-43)$ & $10.1(4-19)$ & 39.1 & $11.7(5-20)$ \\
\hline & VTE $<2$ weeks & $21.7(15-32)$ & $29(19-40)$ & $10.1(4-19)$ & $2.9(0-9.2)$ & $13.1(6-22)$ & $20.4(12-31)$ \\
\hline
\end{tabular}

Abbreviations: DVT Deep vein thrombosis, PE Pulmonary embolism, VTE Venous thromboembolism, IVC Inferior vena cava filter, LMWH Low molecular weight heparin, UFH Unfractioned heparin, OD once daily, BID Twice daily, IV Intravenous, SC subcutaneous.

*Special populations were defined as extreme body weights $>150 \mathrm{~kg}$ or $<40 \mathrm{~kg}$ or creatinine clearance close to $30 \mathrm{ml} / \mathrm{min}$. 
(23.1\%) only in special populations [such as extreme body weight ( $>150 \mathrm{~kg}$ or $<40 \mathrm{~kg}$ ) or kidney disease (creatinine clearance close to $30 \mathrm{ml} / \mathrm{min}$ )] (Table 1). During long-term treatment, $47 / 69(64.8 \%)$ answered that they never used anti-Xa levels or used it only in special populations, while $13 / 69$ (18.8\%) did so on a weekly or monthly basis in all patients. The use of anti-Xa monitoring varied according to the strategy used for long-term treatment. Among those using intermediate doses, 18\% used some form of anti-Xa monitoring for all patients. Among those using full doses once a day $21 \%$ used some form of antiXa monitoring for all patients; whereas $45 \%$ of those using twice a day full doses used monitoring used some form of anti-Xa monitoring for all patients.

Management during the peri-partum period varied widely according to the time of the diagnosis of PAVTE. In those who had a diagnosis more than 4 weeks before the delivery, 37/69 preferred the use of LMWH twice daily (53.6\%), whereas for those diagnosed within 2 to 4 weeks before delivery 27/69 (39.1\%) physicians favored the use of IV UFH. For those diagnosed within two weeks of delivery an IVC filter in combination with LMWH or IV UFH in more was favored by $37 / 69$ (53.2\%) of the respondents.

No association was identified between physician specialty ( $p$-value $>0.05$ ) and years of practice ( $p$-value $>0.05$ ) with respect to dosing and the use of anti-Xa monitoring.

\section{Discussion}

Our survey suggests that LMWH is the preferred drug for the management of PAVTE but that there is wide variation in dosing strategies and the use of anti-Xa monitoring. A wide variation in strategies used for the initial acute and long term treatment period was found for dosing (once a day vs. twice a day) and for the use of Anti-Xa monitoring corresponding to the different recommendations for anti-Xa monitoring and dosing by available guidelines guidelines $[5,6]$ at the time that the survey was conducted. The most current recommendations by the American College of Chest Physicians (ACCP) Guidelines [1] do not support twice daily dosing or anti-Xa monitoring. One relevant finding was that nearly a quarter of the physicians used a reduced dose strategy for long-term treatment of both DVT and PE. This strategy has been recommended by experts [7] and acknowledge in the last two versions of the ACCP Guidelines [1,5] as an alternative to full dose anticoagulation in selected patients, but has never been correctly tested in this popualtion [8]. Our findings are consistent with the systematic review by Romualdi et al. [9] wide variation in the regimens used for the treatment of PAVTE. Although our findings regarding dosing strategies for long term treatment are similar to prior studies conducted by Voke et al. [3] and Knight et al. [10], our study showed decrease in the use of anti-Xa level monitoring. The study by Voke et al. reported that $76 \%$ of physicians used anti-Xa level during treatment, but did not specifically report the responses for long term treatment period. Finally most of the physicians answering the survey were not obstetricians, a phenomenon also observed in a study by Coppeltone et al. [11]. This finding may represent the current trend wherein the care of patients who develop conditions such as PAVTE during pregnancy is transferred to internal medicine specialists.

Our survey has limitations. Our response rate was low, despite multiple efforts to increase the response rate. Since the initial response rate was low $(<15 \%)$ following the 2 electronic reminders, two additional measures were taken to increase the response rate: 1-the survey was endorsed by three highly respected experts; and 2 -compensation in the form of a voluntary raffle. One factor that could explain our rates is that the number of studies that use e-mail to collect data has been increasing over the last years while the average response rate to the surveys appears to be decreasing $[12,13]$. Finally, we cannot exclude that our results reflect the practice of those with an interest in the management of PAVTE and leading to a bias interpretation of current practices.

In conclusion, our survey shows wide variation in practice regarding LMWH dosing and anti-Xa monitoring in pregnancy associated VTE and calls for trials comparing different long term strategies using LMWH in patients with PAVTE.

\section{Abbreviations \\ PAVTE: Pregnancy associated venous thromboembolism; DVT: Deep vein thrombosis; PE: Pulmonary embolism; VTE: Venous thromboembolism; IVC: Inferior vena cava filter; LMWH: Low molecular weight heparin; UFH: Unfractioned heparin; OD: Once daily; BID: Twice daily; IV: Intravenous; SC: Subcutaneous.}

\section{Competing interests}

The authors have declared that no competing interests exist.

\section{Authors' contributions}

Study concept and design: EG, MC and MR. Analysis and interpretation of data: EG, MC and MR. Drafting of the manuscript: EG, MC and MR. Critical revision of the manuscript for important intellectual content: EG, MC and MR. Statistical analysis: EG, MC and MR. All authors read and approved the final manuscript.

\section{Acknowledgments}

The Thrombosis Interest Group of Canada and the International Society of Obstetric Medicine for their support. Drs. Gándara and Rodger had full access to all of the data in the study and take responsibility for the integrity of the data and the accuracy of the data analysis. Dr. Marc Rodger is a Career Scientist of the Heart and Stroke Foundation of Ontario, a Faculty of Medicine and Department of Medicine Clinical Research Chair and was also supported by the Ministry of Research and Innovation's Early Researcher Award. The Department of Medicine, OHRI and the University of Ottawa provided financial support for Dr. Gándara.

\section{Author details}

${ }^{1}$ From the Thrombosis Program, Division of Hematology, Department of Medicine, University of Ottawa-The Ottawa Hospital, Ottawa, Canada. 
${ }^{2}$ Clinical Epidemiology Unit, Ottawa Health Research Institute, Ottawa, Canada. ${ }^{3}$ Ottawa Hospital-Ottawa Hospital Research Institute, General Campus-Centre for Practice Changing Research, 501 Smyth Road, Rm L2269e, Ottawa ONT K1H 8 L6, Canada.

Received: 12 July 2013 Accepted: 1 May 2014

Published: 2 June 2014

\section{References}

1. Bates SM, Greer I, Middeldorp S, Prabulos A, Vandvik PO, VTE, Thrombophilia, Antithrombotic Therapy, and Pregnancy: Antithrombotic therapy and prevention of thrombosis, 9th ed: American college of chest physicians evidence-based clinical practice guidelines. Chest 2012, 141:e691S-e736S.

2. Sephton V, Farquharson RG, Topping J, Quenby SM, Cowan C, Back DJ, Toh CH: A longitudinal study of maternal dose response to low molecular weight heparin in pregnancy. Obstet Gynecol 2003, 101:1307-1311.

3. Voke J, Keidan J, Pavord S, Spencer NH, Hunt BJ, British Society for Haematology Obstetric Haematology Group: The management of antenatal venous thromboembolism in the UK and Ireland: a prospective multicentre observational survey. Br I Haematol 2007, 139:545-558.

4. Middeldorp S: How I, treat pregnancy-related venous thromboembolism Blood 2011, 118:5394-5400

5. Bates SM, Greer IA, Pabinger I, Sofaer S, Hirsh J: American college of chest physicians. venous thromboembolism, thrombophilia, antithrombotic therapy, and pregnancy: American college of chest physicians evidence-based clinical practice guidelines (8th Edition). Chest 2008, 133(6):844S-886S

6. Greer IA: Thomson A.J for the Guidelines and Audit Committee of the Royal College of Obstetricians and Gynaecologists. In The Acute Management of Thrombosis and Embolism During Pregnancy and the Puerperium. London, United Kingdom: Revised version of the Green Top quideline 37b Royal College of Obstetricians and Gynaecologists; 2010. Accesed online at http://www.rcog.org.uk/files/rcog-corp/GTG37b_230611. pdf on April 30th 2014

7. Rodger M: Evidence base for the management of venous thromboembolism in pregnancy. Hematology Am Soc Hematol Educ Program 2010, 2010:173-180

8. Gándara $\mathrm{E}$, Carrier M, Rodger MA: Intermediate doses of low-molecular-weight heparin for the long-term treatment of pregnancy thromboembolism. A systematic review. Thromb Haemost 2013, 111(3):559-561.

9. Romualdi E, Dentali F, Rancan E, Squizzato A, Steidl L, Middeldorp S, Ageno W: Anticoagulant therapy for venous thromboembolism during pregnancy: a systematic review and a meta-analysis of the literature. J Thromb Haemost 2013, 11:270-281.

10. Knight $\mathrm{M}$, UKOSS: Antenatal pulmonary embolism: risk factors, management and outcomes. BJOG 2008, 115:453-461.

11. Copplestone JA, Pavord S, Hunt BJ: Anticoagulation in pregnancy: a survey of current practice. Br J Haematol 2004, 124:124-125.

12. Kaplowitz MD, Hadlock TD, Levine R: A comparison of web and mail survey response rates. Public Opinion Quarterly 2004, 68(1):94-101.

13. Strabac $Z$, Aalberg T: Measuring political knowledge in telephone and web surveys: a cross-national comparison. Soc Sci Comput Rev 2011, 29(2):175-192.

\section{Submit your next manuscript to BioMed Central and take full advantage of:}

- Convenient online submission

- Thorough peer review

- No space constraints or color figure charges

- Immediate publication on acceptance

- Inclusion in PubMed, CAS, Scopus and Google Scholar

- Research which is freely available for redistribution 